\title{
反強磁性酸化物表面の電子状態と磁性
} 一第一原理計算一

\author{
小口多美夫・籾田 浩義* \\ 広島大学大学院先端物質科学研究科 焉 739-8530 広島県東広島市鏡山 1-3-1 \\ *東京大学生産技術研究所 画 153-8505 東京都目黒区駒場 4-6-1
}

（2004 年 10 月 4 日受理）

\section{Electronic Structure and Magnetism of Antiferromagnetic Oxide Surface -First-principles Calculation-}

Tamio OGUCHI and Hiroyoshi MomidA *

Hiroshima University, ADSM, 1-3-1 Kagamiyama, Higashihiroshima, Hiroshima 739-8530

${ }^{*}$ University of Tokyo, Institute of Industrial Science, 4-6-1 Komaba, Meguro-ku, Tokyo 153-8505

(Received October 4, 2004)

\begin{abstract}
Recent first-principles studies on antiferromagnetic oxide surfaces of $\mathrm{MnO}(001)$ and $\mathrm{NiO}(001)$ are reviewed. By structural optimization for the surface relaxation, small surface contraction and rampling relaxation where the surface transitionmetal ions are displaced outwards are obtained. Surface electronic structures of the both oxides are still insulating and the spin magnetic moment at the transition-metal site is almost unchanged from its bulk value. The most interesting feature is the existence of finite spin magnetic moment at the surface oxygen site despite of no moment at oxygen in bulk by symmetry. The surface spin density distribution may be possibly observed by using exchange force microscopy technique recently proposed.
\end{abstract}

\section{1.は じめに}

表面や界面では，表面・界面垂直方向の並進対称性お よびバルク内部で存在する回転対称性の一部が消失する ためバルクとは質的に変わった電子状態が実現されるこ とが期待され，これに起因して種々の興味ある物性の発 現が知られている。また, 特に表面は外部に曝露されて いるため, 原子や分子による修飾や化学反応・触媒過程 の舞台になり, 物理学から化学にわたり広い研究分野を 形成している。さらに, 近年の走査トンネル顕微鏡 (STM: Scanning Tunnelling Microscopy) や原子間力顕微鏡 (AFM: Atomic Force Microscopy）等の原子プローブに関わる測 定技術の進展1)により, 表面の構造を原子スケールで観 測することが可能となり, 表面における特異な物性が 徐々に解き明かされつつある。

E-mail: oguchi@hiroshima-u.ac.jp
表面や界面における磁性は, 応用面からも注目されて いるが，特に遷移金属系の表面や界面においては電子状 態の変化により磁性の発現やエンハンスメントが期待さ れ，その微視的機構の解明に関する研究が活発に行われ ている。その中でも, 第一原理計算に基づく研究は, 表 面界面の安定構造を非経験的に決定し, 磁気モーメント を定量的に予測することが可能で, 原子プローブの実験 と相補的な意味で重要な役割をもっている2)。

これまで, 表面磁性に関する第一原理的研究は遷移金 属系を中心に行われてきたが，反強磁性を有する絶縁性 酸化物表面に関する研究はほとんど報告されていない。 本解説では, $\mathrm{MnO}$ および $\mathrm{NiO}$ の表面構造と磁性に関す る第一原理的な研究3 5) の紹介を行う。

$\mathrm{MnO}$ と $\mathrm{NiO}$ は, $\mathrm{FeO} や \mathrm{CoO}$ と同様に, $\mathrm{NaCl}$ 型の結 晶構造をもち, 第二種反強磁性体として知られている。 第二種反強磁性構造は, Fig. 1 に示すように, (111) 面 上の遷移金属イオンの磁気モーメントが強磁性的に配列 


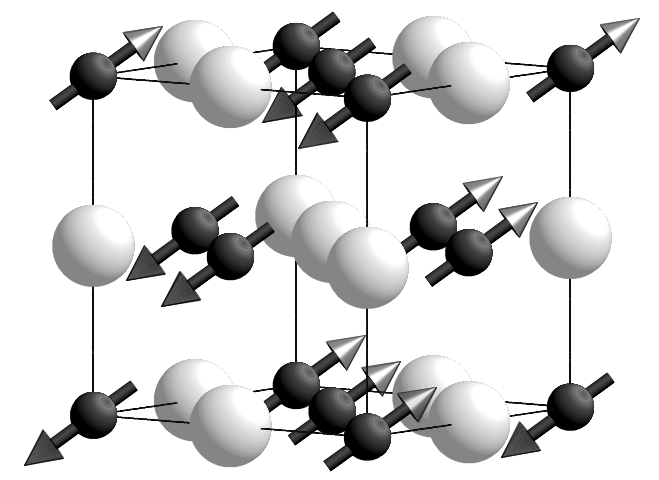

Fig. 1. Crystal and magnetic structure of transition-metal mono-oxides, where up and down arrows denote up and down spin at the transition-metal sites (dark gray). Light gray spheres represent $\mathrm{O}$ atoms.

し， [111］方向に互い違いに並んだ磁気秩序となってい る。反強磁性状態では立方晶からのわずかな格子歪があ る。バルク環境においては, 酸素イオン位置は反対方向 を向いた磁気モーメントをもつ遷移金属イオンに六配位 で囲まれているため, その対称性から有限の磁気モーメ ントは存在しない。しかしながら, 表面酸素位置では真 空側の最近接遷移金属イオンがなくなるため, 対称性の 低下から有限の磁気モーメントをもつことが可能とな る。

\section{2. 計 算 手 法}

ここでの電子状態計算は局所スピン密度近似（LSDA: Local Spin Density Approximation）の範囲での密度汎関 数理論6, 7)に基づき, Kohn-Sham 方程式は全電子フルポ テンシャル線形補強平面波 (FLAPW: Full-potential Linear Augmented Plane Wave） 法8) によりセルフコンシステン トに解かれる。スピン軌道相互作用以外の相対論的効果 はスカラー相対論の手法で考慮されている。スカラー相 対論の範囲では, スピンは量子力学的状態のよい量子数 であるので, スピン $\sigma$ の電子密度関数は

$$
n^{\sigma}(\mathbf{r})=\sum_{i, \mathbf{k}}^{\text {occ. }}\left|\psi_{i} \mathbf{k} \sigma(\mathbf{r})\right|^{2}
$$

で与えられる。ここで, $\psi_{i}^{\mathrm{k} \sigma}$ は Kohn-Sham 方程式の解 である波数 $\mathbf{k}$, バンド指数 $i$ の一電子波動関数である。 スピン密度関数は

$$
m(\mathbf{r})=n^{\uparrow}(\mathbf{r})-n^{\downarrow}(\mathbf{r})
$$

で定義され, ある原子 $\alpha$ の周りに仮定されたマフィン ティン球（半径 $s_{\alpha}$ ) の中での積分值として（ $g$ 因子を 2 と仮定して）スピン磁気モーメントは

$$
M_{\mathrm{s}}(\alpha)=\mu_{\mathrm{B}} \int_{r_{\alpha} \in s_{\alpha}} m(\mathbf{r}) d \mathbf{r} \alpha
$$

となる。ここで, $\mu_{\mathrm{B}}$ はボーア磁子 $(=e h / 2 m c=0.927$ $\times 10^{-20} \mathrm{emu}$ ) である。

Fig. 1 に示した第二種反強磁性 $\mathrm{MnO}$ と $\mathrm{NiO}$ の平衡格 子定数を決定するために, バルク相での全エネルギー計 算を実行し, $\mathrm{MnO}$ に対して $4.335 \AA$ (実験值 $4.445 \AA$ ), $\mathrm{NiO}$ に対して $4.084 \AA$ （実験値 $4.168 \AA$ ）を得た。実際の 結晶では, 小さな菱面体晶的な磁気的歪みが観測されて いるが，本研究ではその歪みは議論の対象とはしない。 加圧下での磁気的歪みに関する第一原理的な研究につい ては文献9,10)を参考にするとよい。

$\mathrm{MnO}$ (001) および $\mathrm{NiO}$ (001) 表面の計算を実行する ために，上で得たバルク相の平衡格子定数を面内方向の 格子定数としてもつ周期的スラブ構造を仮定し, 原子に 働く力の計算から全ての原子位置に関して構造最適化を 行う。面間の緩和の大きさの程度や中心層での電子状態 の様子から, $\mathrm{MnO}(001)$ および $\mathrm{NiO}(001)$ 表面系では 9 層のスラブモデルで十分であることがわかり，これを用 いることとした。

\section{3. 表面構造緩和}

ここで対象としているような化合物系の表面では，表 面に垂直方向の層としての構造緩和に加えて異種原子が 異なる変位を示すいわゆるランプリング緩和が起こる。 イオン結晶系の場合, イオン半径と分極の考察11, 12) ら, 一般に, 陰イオンが外側に, 陽イオンが内側になる ランプリングを起こすと信じられているが，遷移金属酸 化物系の多くの場合，そのランプリングは観測するには たいへん小さい。

表面垂直方向の第 $i$ 層に対する, 層としての緩和 $D_{i}$ とランプリング緩和 $R_{i}$ を次のように定義する。

$$
\begin{aligned}
& D_{i}=\frac{\Delta z i^{a}+\Delta z i^{c}}{2 d_{0}} \\
& R_{i}=\frac{\Delta z i^{a}-\Delta z i^{c}}{d_{0}}
\end{aligned}
$$

ここで, $\Delta z_{i}{ }^{a}$ と $\Delta z_{i}{ }^{c}$ は, それぞれ表面垂直方向の陰个 オンと陽イオンのバルク位置からの変位量を示す。また, $d_{0}$ はバルク相での平衡面間距離である。変位は表面真 空側（[001］方向）を正に仮定しているので, 正（負） 符号のランプリングは陰（陽）イオンが表面外側へ変位 することを意味する。Table 1 と 2 に $\mathrm{MnO}(001)$ および $\mathrm{NiO}$ (001) 表面での最適化された表面緩和を示す。変位 量は最大でも表面位置で $0.05 \AA$ でありたいへん小さい。 $\mathrm{MnO}, \mathrm{NiO}$ ともにランプリングは負であり陰イオンが 表面内側へ緩和する。変位の大きさは第 3 層以下では $0.01 \AA ̊$ より小さく $\mathrm{NiO}$ に対しては低エネルギー電子回折 （LEED）の実験13，14)が報告されており, 実験の誤差の 範囲でよく一致している。ごく最近, $\mathrm{MnO}$ および $\mathrm{NiO}$ 
Table 1. Calculated $i$-th layer atomic displacement from unrelaxed position $\Delta z_{i}$ in $\AA$ toward [001] direction, relaxation $D_{i}$ and rumpling $R_{i}$ in \% for $\mathrm{MnO}(001)$.

\begin{tabular}{lcccc}
\hline \multicolumn{1}{c}{ Site } & $\Delta z_{i}^{\mathrm{Mn}}(\AA)$ & $\Delta z_{i}^{\mathrm{O}}(\AA)$ & $D_{i}(\%)$ & $R_{i}(\%)$ \\
\hline Surface & -0.028 & -0.038 & -1.5 & -0.5 \\
Second & +0.013 & -0.017 & -0.1 & -1.4 \\
Third & +0.003 & +0.004 & +0.2 & +0.0 \\
Fourth & +0.002 & +0.004 & +0.1 & +0.1 \\
\hline
\end{tabular}

Table 2. Calculated $i$-th layer atomic displacement from unrelaxed position $\Delta z_{i}$ in $\AA$ toward [001] direction, relaxation $D_{i}$ and rumpling $R_{i}$ in \% for $\mathrm{NiO}(001)$.

\begin{tabular}{lcccc}
\hline \multicolumn{1}{c}{ Site } & $\Delta z_{i} \mathrm{Ni}(\AA)$ & $\Delta z i{ }^{\mathrm{O}}(\AA)$ & $D_{i}(\%)$ & $R_{i}(\%)$ \\
\hline Surface & -0.002 & -0.053 & -1.4 & -2.5 \\
Second & +0.010 & -0.029 & -0.5 & -1.9 \\
Third & +0.002 & -0.003 & -0.1 & -0.3 \\
Fourth & -0.001 & +0.005 & +0.1 & +0.3 \\
\hline
\end{tabular}

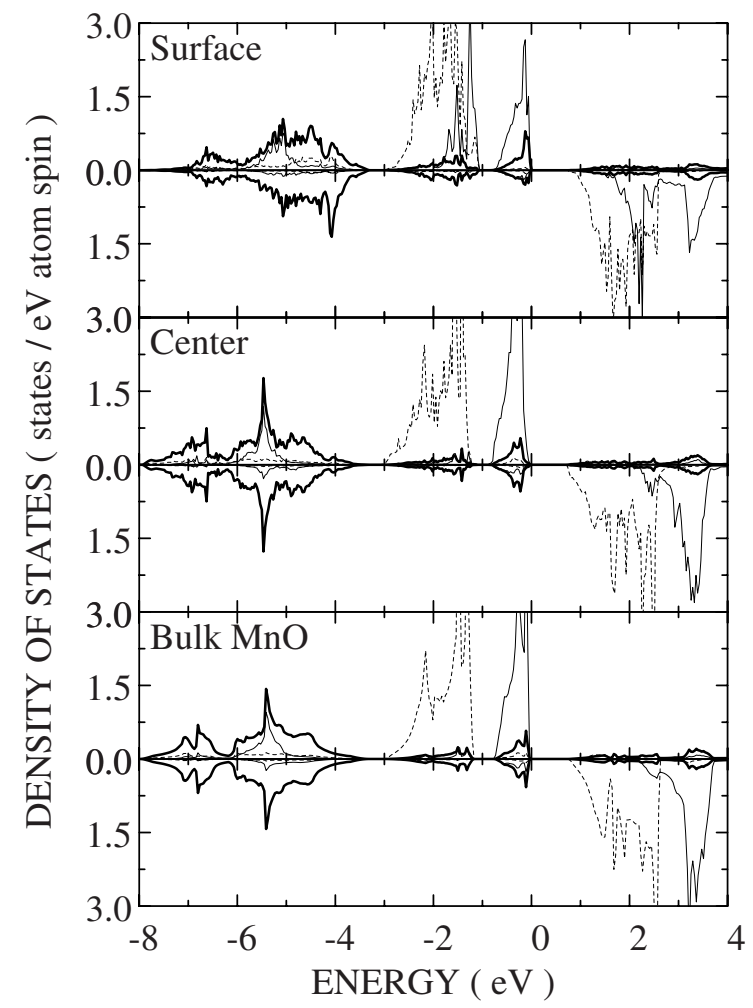

Fig. 2. Calculated partial density of states of surface and center layers in nine-layer $\mathrm{MnO}(001)$. Thick and thin solid, and broken lines denote O-p, Mn- $d e_{g}$ and $t_{2 g}$ states, respectively. Top and bottom panels represent the majority and minority spin states, respectively, of each layer. Top of the valence band is taken at the origin of energy. Partial density of states for bulk $\mathrm{MnO}$ is also shown for comparison.

表面に対してイオン散乱による表面構造測定が行わ れ15，16)，計算と良く一致した結果が報告されている。

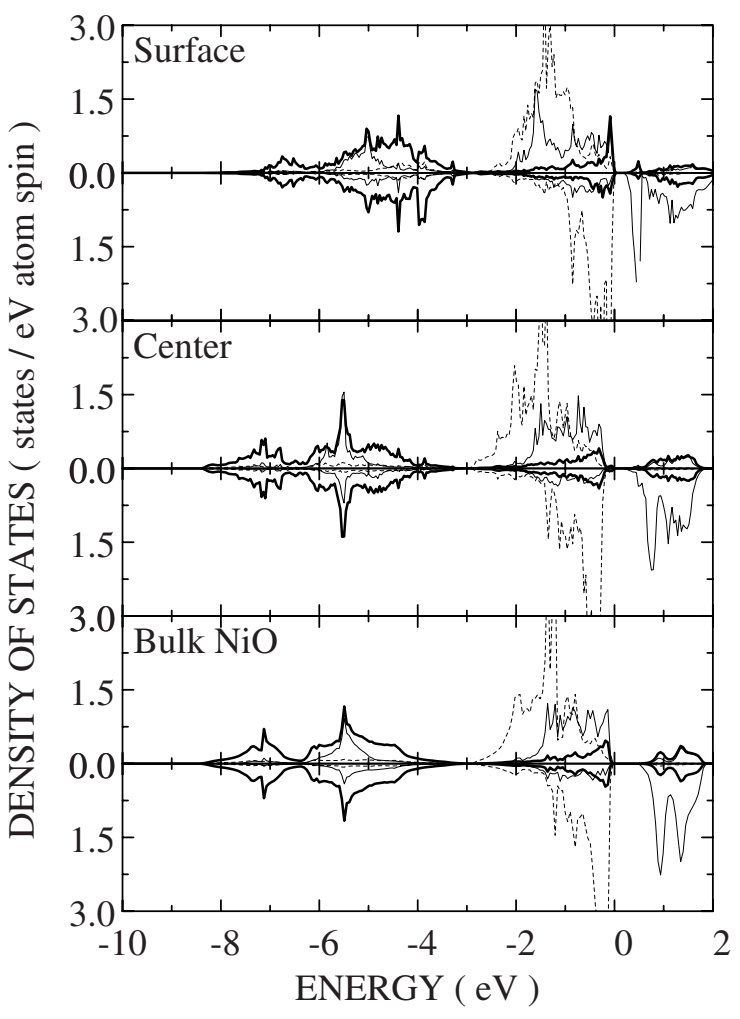

Fig. 3. Calculated partial density of states of surface and center layers in nine-layer $\mathrm{NiO}(001)$. Thick and thin solid, and broken lines denote $\mathrm{O}-p, \mathrm{Ni}-d e_{g}$ and $t_{2 g}$ states, respectively. Top and bottom panels represent the majority and minority spin states, respectively, of each layer. Top of the valence band is taken at the origin of energy. Partial density of states for bulk $\mathrm{NiO}$ is also shown for comparison.

\section{4. 表面電子状態}

$\mathrm{MnO}(001)$ および $\mathrm{NiO}(001)$ 系に対して計算された 遷移金属イオンの $d$ の $e_{g}$ と $t_{2 g}$ 軌道と酸素 $p$ 軌道に射 影した部分状態密度を，それぞれ Fig. 2 と 3 に示す。部 分状態密度は表面層と中心層について描かれているとも に, 比較のためバルク相での結果も載せている。 $\mathrm{MnO}$ と $\mathrm{NiO}$ の第二種反強磁性バルク相に対して, LSDA 計 算はその值は小さいもののエネルギーギャップを与え, 少なくとも基底状態に関しては絶縁相であることを予測 する17 19)。 $\mathrm{MnO}$ ではそのエネルギーギャップが交換分 裂による Mn- $d$ 状態の多数スピンと小数スピンの状態間 に存在し, 表面となってもギャップ近傍の電子状態に本 質的な変化はない。一方, $\mathrm{NiO}$ の場合には, ギャップが 少数スピンの $t_{2 g}$ と $e_{g}$ 状態間, すなわち結晶場分裂内に 存在するため, 表面ができることにより結晶場分裂が小 さくなりギャップ内に表面層にほぼ局在した状態が現れ る。しかしながら，そのギャップ内バンドは分散が小さ いためギャップを埋めるに至らず，LSDA の範囲におい 
てもギャップは維持される。このため, 次節に示すよう に, 遷移金属サイトのスピン磁気モーメントは表面とバ ルクでほとんど変化を示さない結果を導く。 $\mathrm{NiO}(001)$ でギャップ内に現れた状態の波動関数を調べると, ほぼ $\mathrm{Ni}-d$ の $3 z^{2}-r^{2}$ の性格をもっている。この軌道は表面 真空側に広がりを持っており, バルク相で酸素の $p$ 軌 道との反結合状態であったものが，表面ができたことで その $p$ との混成がなくなりギャップ内に現れたものと 考えられる。また, この軌道の表面内方向への広がりは 小さく, バンド分散がほとんどなくなっている。

Fig. 2 と 3 で, 酸素の $p$ 軌道の部分状態密度を見ると, 表面サイトでエネルギー的に重心が高くなっていること がわかる。これは, 表面では近接原子の欠落によりポテ ンシャルが浅くなっていることに起因している。バルク ではその反強磁性の対称性から酸素の $p$ 状態密度はス ピンに依らない。表面系でも第三層以下ではバルクと本 質的に同じ状況が実現している。しかしながら, 表面近 傍では, 表面での軌道混成の欠落によって酸素の $p$ 状 態密度にスピンによる違いが見られる。このことは, 酸 素サイトでの有限のスピン磁気モーメントに導くことに なる。

\section{5. スピン密度と磁気モーメント}

スピン密度は LSDA 計算における（変分原理に基づ く）基本量の 1 つである。（2）式に定義されたように, スピン密度は上向きスピンと下向きスピンの電子密度の 差であるので, 一般的に, スピン密度関数はフェルミ準 位近傍の電子状態を反映している。遷移金属やその化合 物系では, スピン密度は部分的に占有された $d$ 殼に起 因するため電子密度と比べて異方的な分布を示す。

Fig. 4 に $\mathrm{MnO}$ (001) と $\mathrm{NiO}(001)$ 表面系の（100）断 面でのスピン密度を示す。また, Table 3 に各サイトに おけるスピン磁気モーメントの大きさを示す。 $\mathrm{MnO}, \mathrm{NiO}$ ともに, 中心層はバルク様の分布を示す。 $\mathrm{MnO}$ の場合, $\mathrm{Mn}$ サイト周りの分布はほぼ球対称性をもっている。こ れは $\mathrm{Mn}-d$ の多数スピン状態がほとんど占有され小数ス

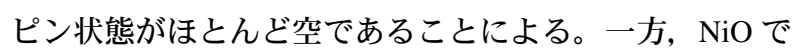
は小数スピンの Ni- $d$ の $e_{g}$ 状態だけが空であることによ りその軌道の形をしたスピン密度を見ることができる。 酸素サイト周りでもスピン密度の分布を見ることができ る。しかしながら, その対称性から中心層サイトでの積 分値，すなわちスピン磁気モーメントは 0 である。

表面層では，特に酸素サイトで大きな変化が起こる。 バルクと比べて対称性が下がったために, 酸素サイトに 有限のスピン磁気モーメントを導く。酸素サイトでのス ピン磁気モーメントはすぐ下の Mn もしくは Ni の磁気

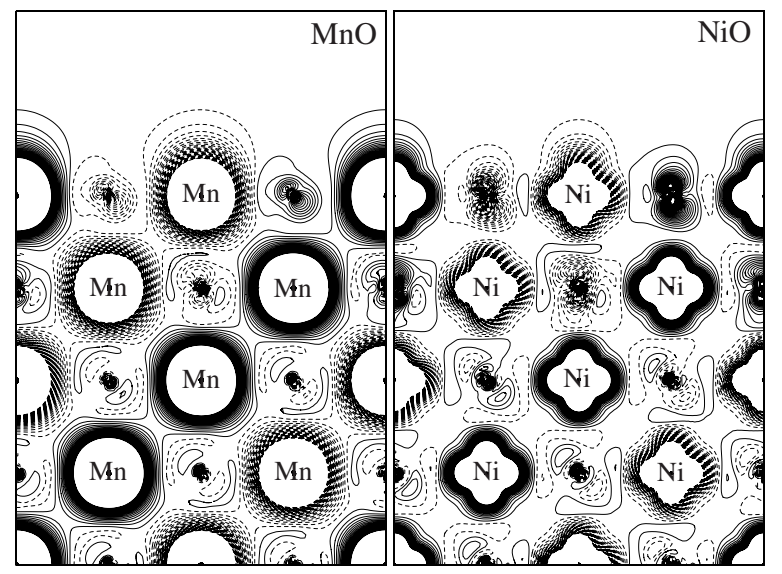

Fig. 4. Calculated spin density distribution $m(\mathbf{r})$ of ninelayer $\mathrm{MnO}(001)$ and $\mathrm{NiO}(001)$ on (100) crosssection. Solid and dashed lines indicate positive and negative density, respectively. Contour lines are plotted from +0.05 to -0.05 , with an interval of 0.002 in $\mu_{\mathrm{B}} / a_{0}{ }^{3}$ where $a_{0}$ is the Bohr radius. Note that high density regions around $\mathrm{Mn}$ and $\mathrm{Ni}$ atoms are not shown.

Table 3. Calculated spin magnetic moment $M_{\mathrm{s}}$ in $\mu_{\mathrm{B}}$ for nine-layer $\mathrm{MnO}(001)$ and $\mathrm{NiO}(001)$. Calculated results for bulk $\mathrm{MnO}$ and $\mathrm{NiO}$ are also shown for comparison. These values are evaluated inside muffin-tin radius of $1.1 \AA$ for $\mathrm{Mn}, 1.0 \AA$ for $\mathrm{Ni}$ and $0.8 \AA$ for $\mathrm{O}$.

\begin{tabular}{lcccccc}
\hline & \multicolumn{2}{c}{$\mathrm{MnO}$} & & \multicolumn{2}{c}{$\mathrm{NiO}$} \\
\cline { 2 - 3 } \cline { 5 - 6 } Site & $\mathrm{Mn}$ & $\mathrm{O}$ & & $\mathrm{Ni}$ & $\mathrm{O}$ \\
\hline Surface & 4.13 & 0.04 & & 1.18 & 0.07 \\
Second & 4.10 & 0.02 & & 1.18 & 0.05 \\
Third & 4.10 & 0.00 & & 1.12 & 0.01 \\
Fourth & 4.10 & 0.00 & & 1.18 & 0.00 \\
Center & 4.10 & 0.00 & & 1.17 & 0.00 \\
Bulk & 4.10 & 0.00 & & 1.16 & 0.00 \\
\hline
\end{tabular}

モーメントと平行である。酸素サイトでのスピン密度の 形状は $\mathrm{MnO}$ と $\mathrm{NiO}$ で異なっている。スピン密度分布は, $\mathrm{MnO}$ では [111] 方向を向いているけれども, $\mathrm{NiO}$ では [001］方向に変わる。これは, $\mathrm{MnO}$ と $\mathrm{NiO}$ での $d-p$ 軌 道混成の微妙な違いに依っていると考えられる。前節の 部分状態密度で見たように, $\mathrm{MnO}$ では多数スピン $d$ 状 態が占有され少数スピン $d$ 状態が空いている。表面 Mn サイトでも同じ状況であり, 表面酸素サイトもバルクと 類似の状況が起こる。ただし, 真空側への混成がなくな った分, 酸素サイトにも両スピン状態のバランスが崩れ スピン磁気モーメントが発生する。そのため, 表面酸素 サイトでのスピン密度分布は, 第二種反強磁性の対称性 を残してバルク様の [111］方向を向く。一方, $\mathrm{NiO}$ で は, スピン磁気モーメントを生み出す正孔は少数スピン 
の $d$ の $e_{g}$ 軌道に由来しているので, 表面酸素サイトで はその軌道と直接的な結合状態をつくっている $p_{z}$ 軌道 が大きく混成の変化を受け, $p$ 様のスピン密度分布が導 かれるものと考えられる。

Table 3 に示すように, 表面酸素サイトでのスピン磁 気モーメントは $0.07 \mu_{\mathrm{B}}$ あり, 第三層以下はバルクのよ うに無視できるくらい小さい。さらに, 表面酸素サイト のスピン密度は表面に垂直方向に分布をもっているの で，スピン偏極の原子プローブによる表面観察の実験は たいへん興味深い。そのような研究の試みを次節に紹介 する。

\section{6. $\mathrm{NiO}$ 表面の交換力顕微鏡イメージ}

交換力顕微鏡（EFM: Exchange Force Microscopy）は 非接触型 AFM のスピン版であり, 強磁性探針を用いて 表面におけるスピン密度をイメージングする手法であ る。EFM は磁気力顕微鏡（MFM: Magnetic Force Microscopy）と類似の実験構成であるが，MFM では探針と表 面の距離を比較的確保して磁気双極子相互作用による磁 区観察を意図している一方で，EFM では探針と表面の 距離をÅの程度に置き交換相互作用により原子スケール でのスピン密度分布の観測を狙っている。EFM の実験 的実現に対してはいくつかの研究20 22) が報告されてお り, また, 第一原理計算からの交換力の大きさの評 価23，24)がなされている。ここでは，その第一原理計算 手法を反強磁性の $\mathrm{NiO}$ 表面に応用する。ここでは, バ ルク層間距離に固定した（構造緩和を無視した） 5 層の $\mathrm{NiO}$ (001) スラブに加えて, 探針として強磁性 $\mathrm{Fe}$ の単 層を EFM のモデルとする。

計算された探針に働く力を，表面原子層から測った探 針 Fe 原子の高さの関数として Fig. 5 (a) に示す。原子 に働く力が 0 の場所を接触点と考えると, $\mathrm{Ni}$ 上では 2.2 A，酸素上では $1.9 \AA$ であることが読みとれる。接触点 より上で，一般に探針 $\mathrm{Fe}$ 原子は $\mathrm{Ni}$ 原子よりも酸素原子 により強く引かれている。しかしながら, スピンが上向 きと下向きの探針に働く力の差

$$
F_{\text {ex }}=F_{\text {up }}-F_{\text {down }}
$$

として定義される交換力は，酸素サイトより $\mathrm{Ni}$ サイト が大きい。Fig. 5 (b) に交換力を探針の高さの関数とし て示す。 $\mathrm{Ni}$ 上の探針には，高さ $3.4 \AA （$ 接触点からの高

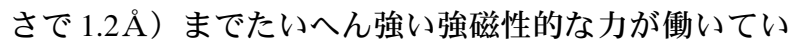
る。その高さ以上では, 交換力は反強磁性的なものに変 わる。一方，酸素上では高さによらず常に反強磁性的な 力が働いている。酸素位置でのスピン磁気モーメントは その直下の $\mathrm{Ni}$ と同じ方向を向いているので，その反強 磁性的な力は酸素を介した第二層 $\mathrm{Ni}$ 原子と探針間の超

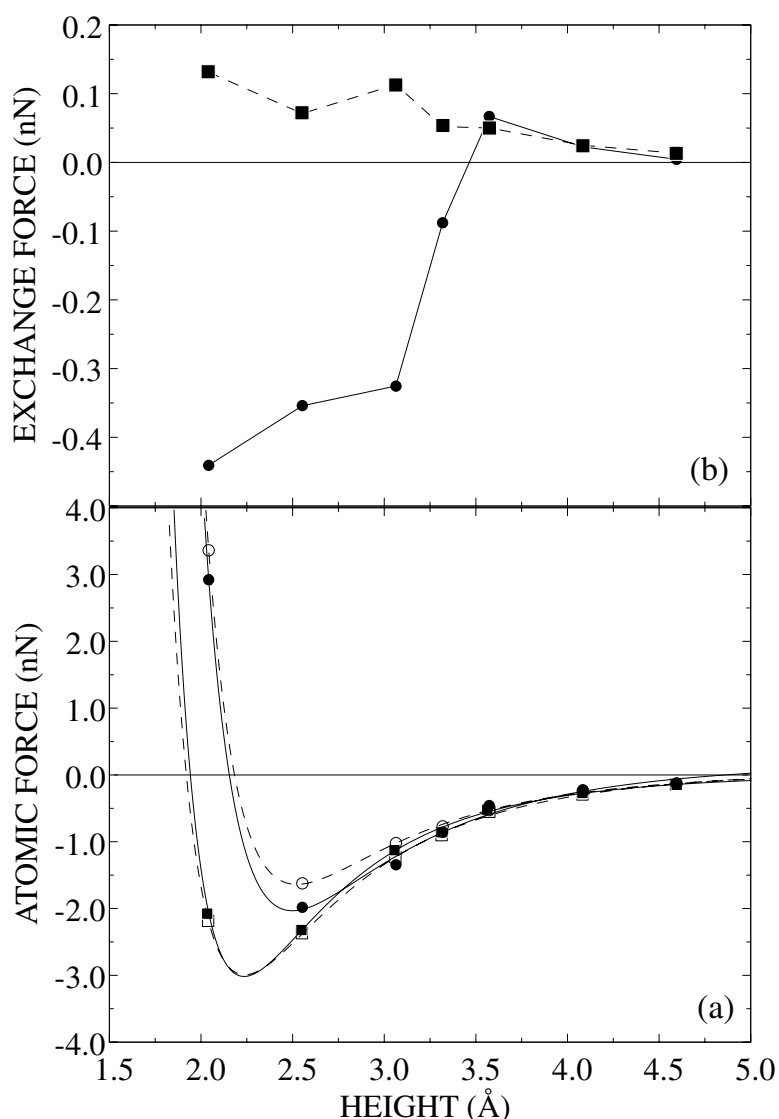

Fig. 5. (a) Calculated atomic forces of $\mathrm{Fe}$ on surface $\mathrm{Ni}$ and $\mathrm{O}$ sites in antiferromagnetic $\mathrm{NiO}(001)$ in $\mathrm{nN}$. Solid (empty) circles and squares denote atomic force of $\mathrm{Fe}$ atom on $\mathrm{Ni}$ and $\mathrm{O}$ sites with parallel (antiparallel) spin moment to that of $\mathrm{Fe}$, respectively. Solid and broken lines are fitted one to spline functions. Probe height is defined as the distance between the Fe mono-layer and the surface layer of $\mathrm{NiO}(001)$.

(b) Exchange force on surface $\mathrm{Ni}$ (solid circles) and $\mathrm{O}$ (solid squares) sites in $\mathrm{nN}$.

交換相互作用的な原因によるものと考えられる。このこ とから, $\mathrm{Ni}$ 上での高さを変えていったときの強磁性的 な力から反強磁性的な力への変化は, $d d$ 間の直接的な 交換相互作用から，より真空側へ拡がった $s p$ 状態を介 した間接的な超交換相互作用への要因の変化とみること ができる。

計算された交換力は $0.1 \mathrm{nN}$ のオーダーであり, 最近 の非接触型 $\mathrm{AFM}$ を用いて十分観測可能な大きさであ る。接触点近傍の高さで，探針を横方向にスキャンさせ たときの交換力を Fig. 6 に示す。これが EFM で期待さ れるスピンイメージである。探針を接触点の約 $1 \AA$ の高 さとしたところ，コントラストは弱いが定性的には同等 のイメージが得られている。Fig. 6 を見ると, 基本的に は [110］方向に第二種反強磁性秩序の（111）強磁性面 を反映した $\mathrm{Ni}$ 原子の反強磁性的なイメージ反転が見ら 


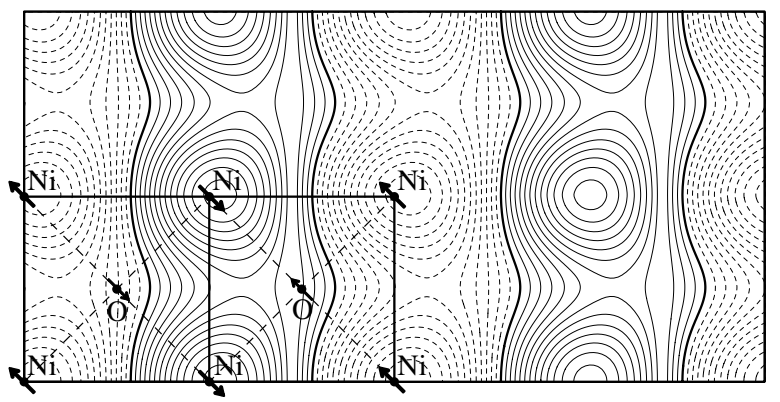

Fig. 6. Lateral dependence of exchange force on surface $\mathrm{Ni}$ and $\mathrm{O}$ sites in antiferromagnetic $\mathrm{NiO}(001)$ surface. Solid and broken lines represent positive and negative exchange forces. Interval of the force is $0.04 \mathrm{nN}$.

れる。酸素上において有限の交換力が働いているのは, 酸素サイトに有限のスピン磁気モーメントが発現したも のを見ているのではないことに注意すべきである。酸素 サイトにはその直下の $\mathrm{Ni}$ と同じ方向に磁気モーメント が発生しており, 交換力は反強磁性的である。つまり, この交換力は酸素サイトの磁気モーメントの原因となっ ている $p_{z}$ 軌道との直接的な交換相互作用によるのでは なく, $p_{z}$ 軌道を介した直下の $\mathrm{Ni}$ との超交換相互作用に よる力を見ているのである。しかしながら，この酸素上 での交換力の大きさはたいへん小さい。実験における EFM イメージの横方向の分解能にも依存するが, $\mathrm{Ni}$ 上 で見られる EFM イメージの非対称性は観測可能である かもしれない。

\section{文献}

1) S. Morita, R. Wiesendanger and E. Meyer (Eds.): "Noncontact Atomic Force Microscopy" (Springer-Verlag, Berlin, 2002); E. Meyer, H.J. Hug and R. Bennewitz (Eds.): "Scanning Probe Microscopy" (Springer-Verlag, Berlin, 2004).

2) M. Weinert and S. Blügel: "Magnetic Multilayers", ed. by L.H. Bennett and R.E. Watson (World Scientific,
1994).

3) H. Momida and T. Oguchi: J. Phys. Soc. Jpn. 72, 588 (2003).

4) H. Momida and T. Oguchi: "Physics of Spin in Solids: Materials, Methods and Applications", ed. by S. Halilov (Kluwer Academic Publishers, 2004) p. 17.

5) H. Momida and T. Oguchi: unpublished.

6) P. Hohenberg and W. Kohn: Phys. Rev. 136, B 864 (1964).

7) W. Kohn and L.J. Sham: Phys. Rev. 140, A 1133 (1965).

8) E. Wimmer, H. Krakauer, M. Weinert and A.J. Freeman: Phys. Rev. B 24, 864 (1981).

9) T. Sasaki: Phys. Rev. B 54, R 9581 (1996).

10) Z. Fang, I.V. Solovyev, H. Sawada and K. Terakura: Phys. Rev. B 59, 762 (1999).

11) R.D. Shannon and C.T. Prewitt: Acta Crystallogr. Sect. B 25, 925 (1969).

12) J.R. Tessman, A.H. Kahn and W. Shockley: Phys. Rev. 92, 890 (1953).

13) C.G. Kinniburgh and J.A. Walker: Surf. Sci. 63, 274 (1977).

14) M.R. Welton-Cook and M. Prutton: J. Phys. C: Solid St. Phys. 13, 3993 (1980).

15) T. Okazawa, Y. Nakagawa and Y. Kido: Phys. Rev. B 69, 125412 (2004).

16) T. Okazawa and Y. Kido: Surf. Sci. 556, 101 (2004).

17) T. Oguchi, K. Terakura and A.R. Williams: Phys. Rev. B 28, 6443 (1983).

18) K. Terakura, T. Oguchi, A.R. Williams and J. Kübler: Phys. Rev. B 30, 4734 (1984).

19) K. Terakura, A.R. Williams, T. Oguchi and J. Kübler: Phys. Rev. Lett. 52, 1830 (1984).

20) K. Mukasa, K. Sueoka, H. Hasegawa, Y. Tazuke and K. Hayakawa: Mater. Sci. Eng. B 31, 69 (1995).

21) H. Hosoi, K. Sueoka, K. Hayakawa and K. Mukasa: Appl. Surf. Sci. 157, 218 (2000).

22) H. Hosoi, M. Kimura, K. Hayakawa, K. Sueoka and K. Mukasa: Appl. Phys. A 72 Suppl., S 23 (2001).

23) K. Nakamura, H. Hasegawa, T. Oguchi, K. Sueoka, K. Hayakawa and K. Mukasa: Phys. Rev. B 56, 3218 (1997).

24) K. Nakamura, T. Oguchi, H. Hasegawa, K. Sueoka, K. Hayakawa and K. Mukasa: Appl. Surf. Sci. 142, 433 (1999). 